Research article

\title{
Are proton pump inhibitors the first choice for acute treatment of gastric ulcers? A meta analysis of randomized clinical trials Maribel Salas $\dagger^{* 1}$, Alexandra Ward $\dagger^{1}$ and Jaime Caro $\dagger^{1,2}$
}

Address: ${ }^{1}$ Caro Research Institute, 336 Baker Avenue, Concord, MA, 01742, USA and ${ }^{2}$ Division of General Internal Medicine, McGill University, Montreal, Canada

E-mail: Maribel Salas* - msalas@ caroresearch.com; Alexandra Ward - alexward@caroresearch.com; Jaime Caro - jcaro@caroresearch.com

*Corresponding author †Equal contributors

Published: 15 July 2002

BMC Gastroenterology 2002, 2:17
Received: 22 March 2002

Accepted: 15 July 2002

This article is available from: http://www.biomedcentral.com/I47I-230X/2//7

(C) 2002 Salas et al; licensee BioMed Central Ltd. Verbatim copying and redistribution of this article are permitted in any medium for any purpose, provided this notice is preserved along with the article's original URL.

\begin{abstract}
Background: Gastric ulcers are a frequent problem in the United States. Proton pump inhibitors have been shown to increase healing rates and improve clinical symptoms. The objective of this study is to compare gastric ulcer healing rates for patients treated with a proton pump inhibitor (PPI) (omeprazole, rabeprazole, pantoprazole, or lansoprazole), an histamine 2- receptor antagonist (ranitidine) or placebo.

Methods: A literature search was conducted to identify randomized, controlled clinical trials that included a PPI in at least one treatment arm and assessed the gastric ulcer healing rates endoscopically. The healing rates were estimated for each treatment at specific time points, and Rate Ratios (RR) and 95\% confidence intervals (Cl) were estimated for each trial.

Results: Sixteen trials met the inclusion criteria: four compared a PPI versus placebo, nine compared a PPI versus ranitidine (no trials of rabeprazole versus ranitidine met the inclusion criteria), and three compared a newer PPI (lansoprazole, pantoprazole or rabeprazole) versus omeprazole. In relation to ranitidine, the pooled RR of PPIs (lansoprazole, omeprazole and pantoprazole) was I.33 (95\% Cl I.24 to I.42) at four weeks. In each trial, greater improvement in the studied clinical symptoms was found with the newer PPIs (rabeprazole, pantoprazole and lansoprazole) when compared to omeprazole.
\end{abstract}

Conclusion: In this study treatment with PPIs resulted in higher healing rates than ranitidine or placebo. This evidence suggests that the first choice for gastric ulcer treatment for the greater relief of symptoms is one of the newer PPIs.

\section{Background}

In the United States about four million people have active peptic ulcers and about 350,000 new cases are diagnosed each year, and approximately 3000 deaths per year in the U.S. are due to gastric ulcer [1]. The primary therapeutic approach to gastric ulcer remains the inhibition of gastric acid secretion to produce symptom relief, acceleration of crater healing and the prevention of relapse or recurrence $[2,3]$, since gastric ulcer can lead to hemorrhage, perforation, obstruction and death $[4,5]$.

It is established that the $\mathrm{H}+, \mathrm{K}+$-ATPase, or proton pump, participates in the final step of acid secretion $[6,7]$ and all the peripheral parietal cell stimuli converge to activate it 
[7]. Therefore, blocking the final process in hydrogen ion secretion reduces acid secretion and this is the mechanism of action of the substituted benzimidazole agents known as proton pump inhibitors (PPI). Currently, five PPIs are marketed: rabeprazole, omeprazole, esomeprazole, lansoprazole and pantoprazole, each with a different pharmacokinetic profile, tissue selectivity, binding specificity and potential to interact with the cytochrome P450 enzyme system [8-10]. For example, rabeprazole and esomeprazole achieve more rapid and profound inhibition of acid secretion than do older agents [10]. It is unclear, however, if these pharmacologic differences lead to distinctions in the clinical efficacy of healing gastric ulcers and controlling ulcer symptoms. To address this question we undertook a meta-analysis of all randomized clinical trials that compared at least one of the newer PPI with either ranitidine or placebo.

\section{Methods}

To identify studies for inclusion in this meta-analysis, two researchers independently conducted searches of MEDLINE $^{\circledast}$, Cochrane Library documents. The keywords used for these searches were: proton pump inhibitors, PPI, rabeprazole, omeprazole, esomeprazole, lansoprazole, pantoprazole, ranitidine; healing rates, gastric ulcer, stomach ulcer, gastric ulcer disease, peptic ulcer, peptic related disorders; and clinical trials, randomized clinical trials and multicenter stud$i e s$. Hand searching of medical journals was carried out as well as review of reference lists of other meta-analyses, monographs, pharmacoeconomic studies and reviews.

The search included papers published between January 1990 to July 2001, with no language limitations.

The two researchers independently reviewed the papers and selected all those described as randomized controlled clinical trials, double blind, short-term treatment (less than six months) in patients with endoscopically confirmed diagnosis of gastric ulcer that also included at least one group treated with a PPI. If a paper did not report healing rates, but reported improvement in clinical symptoms, this could be included for the analyses of symptoms.

The decision regarding whether to include a paper was not related to trial results. Papers related to chemical properties of PPI, pharmacokinetic, pharmacodynamic, acidity studies, concomitant duodenal ulcers or gastric ulcers complicated with hemorrhage or perforation, PPI combined with antibiotics or with treatment of Helicobacter pylori were excluded. Papers or abstracts with insufficient data, preliminary results, duplicate reports of the same trials or with more complete reporting in another paper were also excluded. The two researchers reviewed the studies independently and any differences in the data retrieved from the papers were resolved by consensus. The information entered into a database included: study design, population characteristics, diagnosis, severity, PPI and comparator treatment regimens, healing rates and clinical symptoms as well as alcohol consumption, smoking and caffeine use.

Ulcer diagnosis and healing had to be assessed by endoscopy; we accepted the primary study authors' definition for gastric ulcer diagnosis and healing.

Results were retrieved for both intention to treat and per protocol analysis, if the paper provided such data. If the authors reported per protocol results only and mentioned the initial number of subjects in the study, we estimated the healing rates for the intention to treat analysis.

\section{Statistical analysis}

The healing rate ratio (RR) was calculated for each trial by dividing the healing rate of the PPI by the rate with the comparator at the specified time point. Chi-squares and 95\% confidence intervals (CI) were calculated using the exact method described by Miettinen [11].

The appropriateness of combining results from individual studies was examined using the Wald $\chi^{2}$ for statistical homogeneity. We considered a $p$ value less than 0.05 to be significant for all statistical tests. There were no adjustments for multiple comparisons.

As there was no statistically significant evidence of heterogeneity, the healing rates for each treatment were pooled across trials by time point. Overall healing rates of PPIs at four and eight weeks were estimated by pooling the rates for the recommended daily doses: $30 \mathrm{mg} / \mathrm{d}$ for lansoprazole, $20 \mathrm{mg} / \mathrm{d}$ for omeprazole, $40 \mathrm{mg} / \mathrm{d}$ for pantoprazole. Rabeprazole was pooled using dose of $20 \mathrm{mg} / \mathrm{d}$ at three and six weeks. Individual trial results were weighted using the inverse of the variance of the RR estimated for each trial. The overall RR was then estimated by dividing the weighted average healing rates for each treatment with the estimates for placebo, ranitidine or omeprazole. These overall RR were assessed using the Mantel-Haenszel $\chi^{2}$ test and 95\% CI were calculated using the exact method [11].

To assess the possibility of publication bias, the RR point estimates were plotted against year of publication and sample size. To identify any studies that exerted a disproportionate influence on the summary treatment effect, we deleted individual studies one at a time. To investigate the possible consequences of including abstracts for which we could not obtain full reports, we excluded these data in secondary analyses. 


\section{Results}

Table I: Description of gastric ulcer studies by drug, sample size and dosage. Ital Coop Grp: Italian Cooperative Group, Coop St Group: Cooperative Study Group.

\begin{tabular}{|c|c|c|c|c|c|c|}
\hline Author & Study Drug & $\begin{array}{c}\text { Dose (mg/ } \\
\text { d) }\end{array}$ & $\mathbf{N}$ & Comparator & $\begin{array}{c}\text { Dose (mg/ } \\
\text { d) }\end{array}$ & $\mathbf{N}$ \\
\hline Florent [24] & Lansoprazole & 30 & 60 & Omeprazole & 20 & 66 \\
\hline Witzel [25] & Pantoprazole & 40 & 163 & Omeprazole & 20 & 80 \\
\hline Dekkers [26] & Rabeprazole & 20 & 113 & Omeprazole & 20 & 114 \\
\hline \multirow[t]{3}{*}{ Avner [12] } & Lansoprazole & 15 & 68 & Placebo & & 67 \\
\hline & & 30 & 67 & & & \\
\hline & & 60 & 63 & & & \\
\hline Valenzuela [13] & Omeprazole & 2040 & 202214 & Placebo & & 104 \\
\hline Cloud [14] & Rabeprazole & 2040 & 3231 & Placebo & & 31 \\
\hline Humphries [27] & Rabeprazole & 2040 & 3231 & Placebo & & 31 \\
\hline Bardhan [I5] & Lansoprazole & 3060 & 8285 & Ranitidine & 300 & 83 \\
\hline Michel [16] & Lansoprazole & 30 & 79 & Ranitidine & 300 & 79 \\
\hline Classen [I7] & Omeprazole & 20 & 83 & Ranitidine & 300 & 74 \\
\hline Coop St Group [18] & Omeprazole & 40 & 21 & Ranitidine & 300 & 25 \\
\hline Ital Coop Grp [19] & Omeprazole & 20 & 84 & Ranitidine & 300 & 83 \\
\hline Walan [20] & Omeprazole & 2040 & 203194 & Ranitidine & 300 & 205 \\
\hline Choi [2I] & Omeprazole & 20 & 125 & Ranitidine & 300 & 125 \\
\hline Bader [22] & Pantoprazole & 40 & 192 & Ranitidine & 300 & 123 \\
\hline Hotz [23] & Pantoprazole & 40 & 166 & Ranitidine & 300 & 82 \\
\hline
\end{tabular}

There were more than one thousand papers on PPI, of which 153 focused on PPI use for the treatment of gastric ulcers. Sixteen trials met all the criteria for inclusion (Table 1) [12-27]. Four trials compared a PPI versus placebo nine compared PPI versus ranitidine (no trials of rabeprazole versus ranitidine met the inclusion criteria), and three compared a newer PPI (lansoprazole, pantoprazole or rabeprazole) versus omeprazole. Omeprazole was studied most often (6), followed by lansoprazole (4), rabeprazole (3) and pantoprazole (3). No study on esomeprazole for the treatment of gastric ulcer met the inclusion criteria.

The criteria for diagnosis of gastric ulcer varied: $57 \%$ of the studies required the ulcer size to be 5 to $20 \mathrm{~mm}$ and $43 \%$ required 3 to $25 \mathrm{~mm}$. The majority (95\%) defined healing as the complete re-epithelialization of ulcer crater. The other researchers defined healing, as the endoscopic disappearance of ulcer crater with no visible mucosa breaks. Efficacy results were reported at various time points, ranging from 2 to 8 weeks.

The mean age of the patients in these trials was $56 \pm 1.5$ years. Approximately half the patients smoked but few studies analyzed the healing rates by smoking status. About half the studies reported on alcohol consumption, and $46 \%$ of patients reported alcohol consumption at the baseline visit. Caffeine use was infrequently reported.

\section{Clinical symptoms}

It was not possible to pool these results because different symptoms were reported in each study, at different time points, and also the method used to collect data varied (Table 2). However, individual trials showed more improvement or resolution of pain, day pain and night pain was found with the new PPIs rabeprazole, pantoprazole and lansoprazole compared to omeprazole. For example, $82 \%$ of patients with pain improved with rabeprazole compared to $65 \%$ with omeprazole at 6 weeks [26] (Table 2).

\section{Healing rates}

Healing data are presented for the intention-to-treat analyses as similar results were obtained with the per protocol analysis. For lansoprazole, pantoprazole and omeprazole the results were reported at four and eight weeks and the rabeprazole studies did so at three and six weeks. Therefore, the overall healing rate was obtained at three, four, six and eight weeks.

Healing rates varied between the studies, but were consistently lower with placebo treatment. For the majority of patients receiving placebo treatment the ulcer did not heal during the course of the trial and the maximum recorded as healed was just over a third of the patients (39\%) in any of the trials. Whilst higher healing rates were observed after treatment with ranitidine by the end of the trials the ul- 
Table 2: Symptom improvement or resolution by study, time point and treatment group

\begin{tabular}{|c|c|c|c|c|c|}
\hline \multirow[b]{3}{*}{ Reference } & \multirow[b]{3}{*}{ Symptom } & \multicolumn{4}{|c|}{ Improvement (\%Resolved) } \\
\hline & & \multicolumn{2}{|c|}{ Study Drug } & \multicolumn{2}{|c|}{ Comparator } \\
\hline & & 2 wks & 4 wks & 2 wks & 4 wks \\
\hline \multirow[t]{3}{*}{ Dekkers [26] } & Pain frequency & 7I (34)। & $82(52)^{2}$ & $61(29) !$ & $65(44)^{2}$ \\
\hline & Day pain & $88(60)^{l}$ & $90(75)^{2}$ & $75(59) !$ & $83(67)^{2}$ \\
\hline & Night pain & $82(68) !$ & $89(84)^{2}$ & $79(6 I) !$ & $80(68)^{2}$ \\
\hline Witzel [25] & Pain free & 79 & 88 & 68 & 81 \\
\hline \multirow[t]{2}{*}{ Florent [24] } & Daytime pain & & $86^{3}$ & & $60^{3}$ \\
\hline & Night pain & & 100 & & 70 \\
\hline \multirow[t]{2}{*}{ Bardhan [15] } & Pain free & & $\mathrm{L} 30=75$ & & 65 \\
\hline & & & $\mathrm{L} 60=72$ & & \\
\hline Michel [16] & Epigastric pain relief & & 73 & & 72 \\
\hline \multirow[t]{2}{*}{ Valenzuela [I3] } & Global assessment of Gl symptoms & & $040=49.3$ & & \\
\hline & & & $O 20=40.5$ & & \\
\hline \multirow[t]{3}{*}{ Ital Coop Grp [19] } & Overall symptoms & 75 & 87 & 65 & 80 \\
\hline & Epigastric day pain & 94 & & 92 & \\
\hline & Epigastric night pain & 96 & & 91 & \\
\hline \multirow[t]{2}{*}{ Walan [20] } & Ulcer symptoms free & $040=69$ & & 55 & \\
\hline & & $\mathrm{O} 20=62$ & & & \\
\hline \multirow[t]{6}{*}{ Cloud [14] } & Frequency of symptoms & & $\operatorname{Rab} 20=(64)^{2}$ & & $(28)^{2}$ \\
\hline & & & $\operatorname{Rab} 40=(46)^{2}$ & & \\
\hline & Severity of daytime symptoms & & $\operatorname{Rab} 20=(62)^{2}$ & & $(54)^{2}$ \\
\hline & & & $\operatorname{Rab} 40=(57)^{2}$ & & \\
\hline & Severity of nighttime symptoms & & $\operatorname{Rab} 20=(70)^{2}$ & & $(65)^{2}$ \\
\hline & & & $\operatorname{Rab} 40=(55)^{2}$ & & \\
\hline
\end{tabular}

$\mathrm{w}=$ week, $\mathrm{Rab}=$ rabeprazole, $\mathrm{L}=$ lansoprazole, $\mathrm{O}=$ omeprazole. The number after the letter indicates the dose. $\mathrm{I}:$ three weeks, 2 : six weeks, 3 : eight weeks.

cers remained for at least half the patients (52\%). In contrast, by the end of the trial the ulcers were healed in at least two-thirds of the patients receiving proton pump inhibitors (67\%).

As would be expected, when compared with placebo treatment, the PPIs (lansoprazole and omeprazole) improved the pooled healing RR at each time point. In relation to ranitidine, the pooled healing RR of PPIs (lansoprazole, omeprazole and pantoprazole) was also increased at both four and eight weeks. There were no studies versus rabeprazole. The healing RR in each trial of the newer PPIs was found to be comparable or better than omeprazole at each time point (Figure 1).

\section{Publication bias}

The healing RR was plotted against sample size but there was no trend with increasing size: small studies had healing RR similar to large studies with the same comparator (Figure 2). There was one abstract [27] with data obtained at 3 and 6 weeks, which is not included.

\section{Discussion}

In the absence of active treatment, the majority of patients continued to have a gastric ulcer at the end of the trial. A much higher healing rate was observed when patients received treatment with a PPI when compared to either a placebo or ranitidine. This is consistent with the results obtained for treatment with PPIs when compared to ranitidine for both duodenal ulcers and gastro esophageal reflux disease $[2,28]$. We also found that, there is some evidence of an advantage to prescribing two of the newer PPIs (lansoprazole or pantoprazole) compared to omeprazole for gastric ulcer, since there was a $15 \%$ increase in healing rates at 4 weeks. In addition, the newer PPIs (rabeprazole, lansoprazole and pantoprazole) have all been show to produce superior improvement in clinical symptoms compared to omeprazole at both 2 and 4 weeks [2426].

Relatively few randomized controlled clinical trials have been published on the efficacy of PPI for treating gastric ulcers when compared with gastro esophageal reflux disease or with duodenal ulcers $[29,30]$. This could be due to gastric ulcers being less frequently diagnosed than duodenal ulcer [31], or the importance of clinicians confirming 


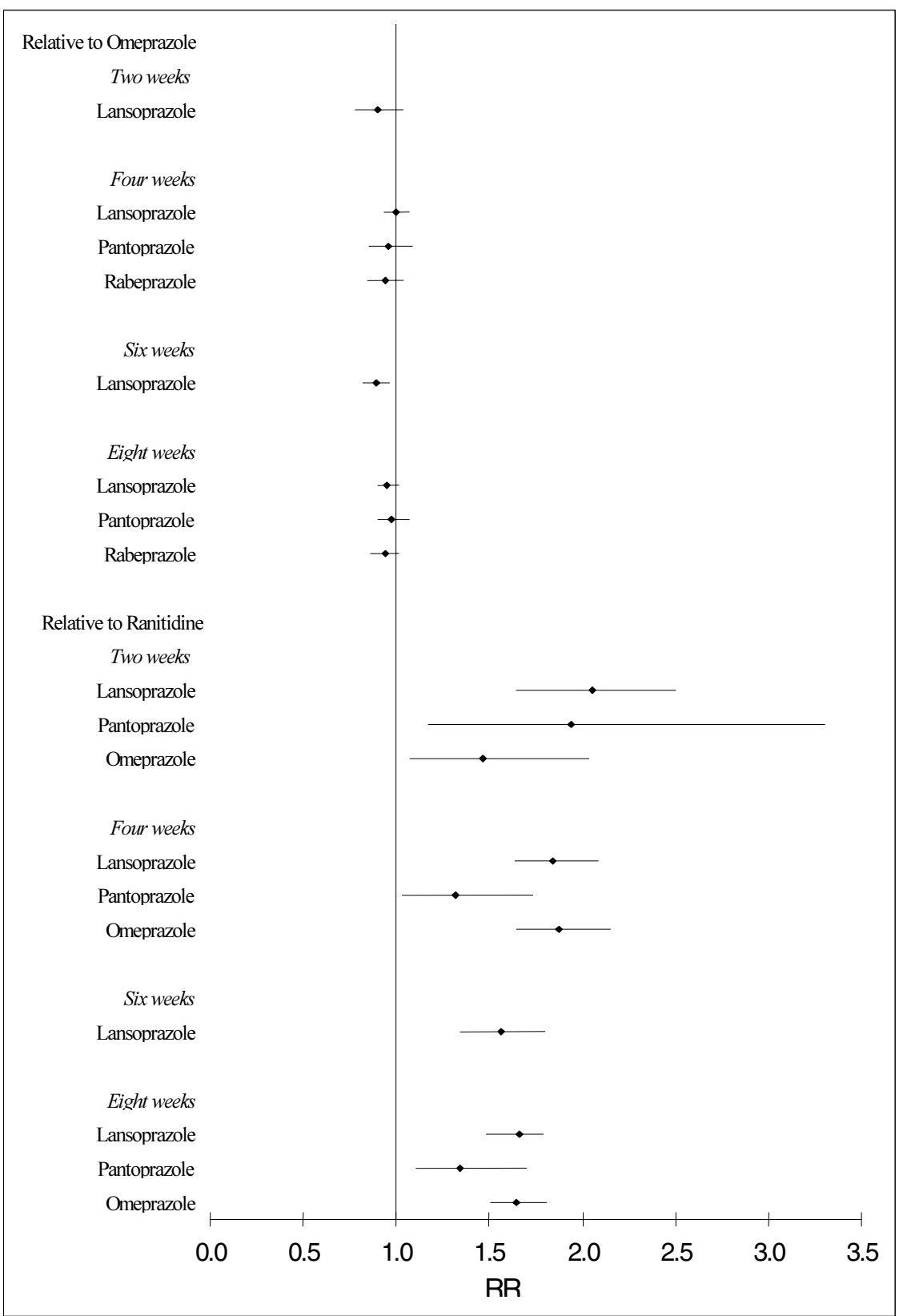

Figure I

Overall healing rate ratios and $95 \% \mathrm{Cl}$ of different proton pump inhibitors versus omeprazole or ranitidine 


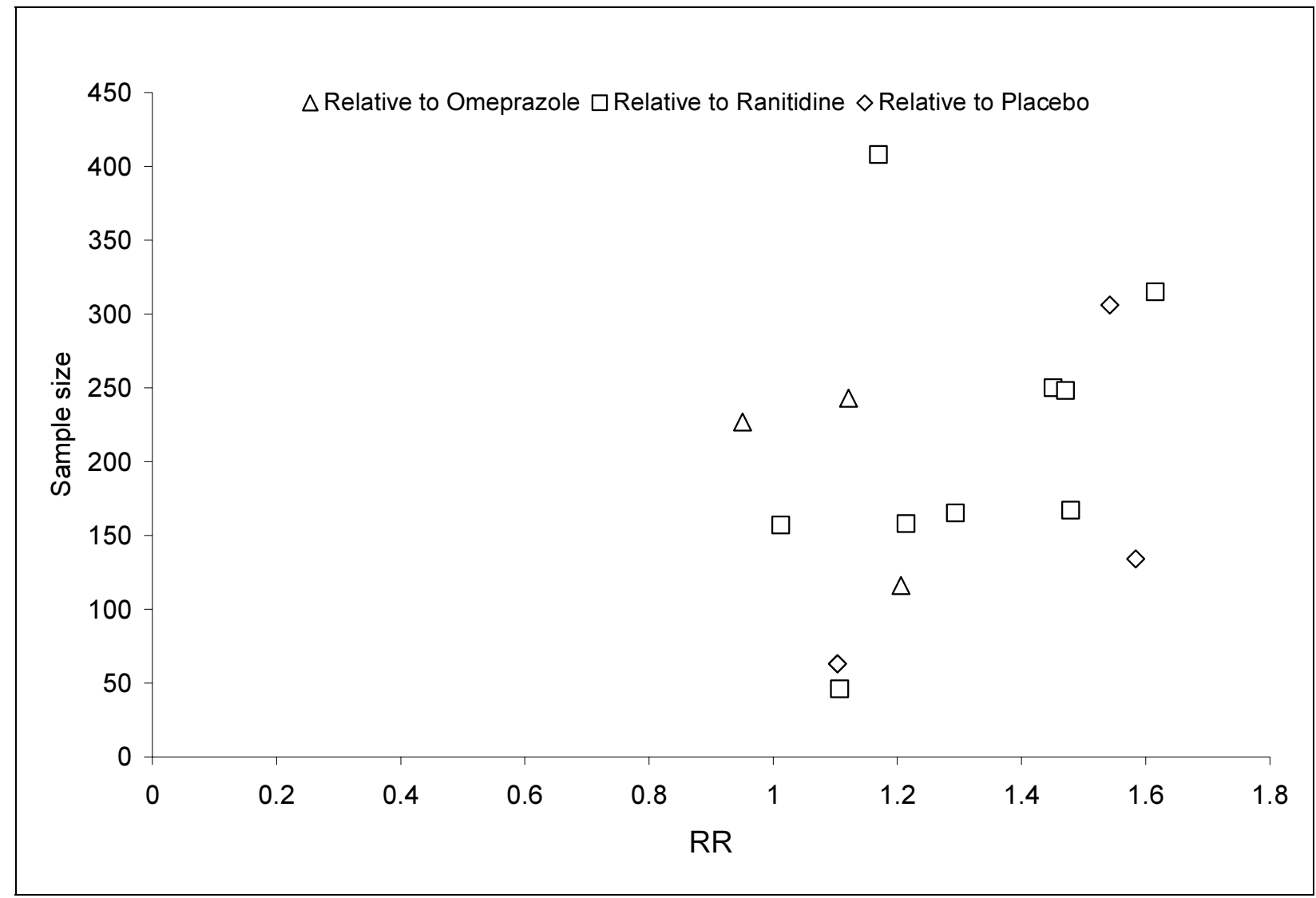

\section{Figure 2}

Healing rate ratios at four weeks versus sample size to explore publication bias

a differential diagnosis between gastric ulcer and gastric cancer. Some authors have also argued that the classification of gastric and duodenal ulcers is artificial, since ulcers could be driven distally or drawn proximally across the arbitrary boundary of the pylorus [32]. Furthermore, some clinical assessments may be complicated as $10-20 \%$ of patients with gastric ulcers also have duodenal ulcers. However, given the severity of the symptoms generally associated with a gastric ulcer, there no longer appears to be a clear justification for continuing to conduct placebocontrolled trials in these patients.

Recent observations have suggested that the duration of treatment with acid secretory inhibitors is more important than the degree of acid inhibition per 24-hours [33]. We could not test the long-term effect of PPIs on ulcer relapse rates, since there was not enough information published. More research into maintenance therapy is clearly re- quired, because the relative long-term efficacy of different treatments, particularly the combination of PPIs with antibiotics, and the effect of dose variation on the relapse and complications from gastric ulcers is not well studied. Other factors known to have an impact on gastric ulcer healing are smoking; alcohol and ulcer size, but the papers did not report the healing results for these subgroups of patients or by those variables. Unfortunately, the researchers reported different clinical symptoms and methods to collect the data and so we could not pool these results.

\section{Conclusions}

This study suggests that the first-line drug therapy for patients diagnosed with gastric ulcer should be a PPI, in preference to an $\mathrm{H} 2$ antagonist. This study indicated that compared with ranitidine the PPIs provide faster onset of action, greater relief of symptoms and increased healing 
rates. However, there is also clearly a need for additional studies to determine the appropriate maintenance doses and understand the factors influencing healing and relapse rates.

\section{Abbreviations \\ PPI: Proton pump inhibitor}

\section{H2A: Histamine 2 receptor antagonist}

\section{RR: Rate ratio}

\section{CI: Confidence intervals}

\section{Competing interests}

This research was supported in part by an unrestricted grant from Janssen Ortho Canada.

\section{Authors' Contributions}

All authors participated in the design, analyses, editing and final approval of the manuscript.

\section{References}

I. Kurata JH, Haile BM: Epidemiology of peptic ulcer disease. Clin Gastroenterol 1984, 13:289-307

2. Florent C: Progress with proton pump inhibitors in acid peptic disease: treatment of duodenal and gastric ulcer. Clin Ther | 993, I 5(suppl B): |4-2|

3. Hasebe T, Harasawa S, Miwa T: Factors affecting depth of gastric ulcers. Tokai J Exp Clin Med 1998, 23:177-182

4. Sontag SI: Guilty as charged: bugs and drugs in gastric ulcer. Am J Gastroenterol 1997, 92: |255-I26।

5. Hasebe T, Harasawa S, Miwa T: Factors affecting depth of gastric ulcers. Tokai J Exp Clin Med 1998, 23:177-182

6. Sachs G, Chang HH, Rabon E, Schackman R, Lewin M, Saccomani G: A non electrogenic $\mathbf{H +}$ pump in plasma membranes of hog stomach. J Biol Chem 1976, 25 I:7960-7968

7. Sachs G, Shin JM, Besancon M, Prinz C: The continuing development of gastric acid pump inhibitors. Aliment Pharmacol Ther 1993, 7(suppl I):4- 12

8. Schepp W: Proton pump inhibitory therapy: then and now. Yale J Biol Med 1996, 69:175-186

9. Earnest DL: Treatment advances in acid secretory disorders: the promise of rapid symptom relief with disease resolution. Am J Gastroenterol I 999, 94(suppl):SI 7-S24

10. Robinson M: New-generation proton-pump inhibitors: overcoming the limitations of early-generation agents. Eur J Gastroenterol Hepatol 200I, I 3(suppl I):S43-47

II. Miettinen OS: Theoretical Epidemiology. Principles of Occurrence Research in Medicine. Delmar Publishers Inc, Ist Edition, New York 1985

12. Avner DL, Movva R, Nelson KJ, McFarland M, Berry W, Erfling W: Comparison of once daily doses of lansoprazole (I5, 30 and $60 \mathrm{mg}$ ) and placebo in patients with gastric ulcer. Am J Gastroenterol 1995, 90:1289-1294

13. Valenzuela JE, Kogut DG, McCullough AJ, Colon Pagan JR, Shah U, Whipple J, Gilde LR, Simon TJ: Comparison of once-daily doses of omeprazole (40 and $20 \mathrm{mg}$ ) and placebo in the treatment of benign gastric ulcer: a multicenter, randomized, doubleblind study. Am J Gastroenterol 1996, 9 I ( I 2):251 6-2522

14. Cloud ML, Enas N, Humphries T], Bassion S: Rabeprazole in treatment of acid peptic diseases: results of three placebo-controlled dose-response clinical trials in duodenal ulcer, gastric ulcer, and gastroesophageal reflux disease (GERD). The Rabeprazole Study Group. Dig Dis Sci 1998, 43:993-1000

15. Bardhan KD, Ahlberg J, Hislop WS, Lindholmer C, Long RG, Morgan AG, Sjostedt S, Smith PM, Stig R, Wormsley KG: Rapid healing of gastric ulcers with lansoprazole. Aliment Pharmacol Ther 1994, 8:215-220

16. Michel P, Lemaire M, Colin R, Bommelaer G, Rambaud JC, Dupas JL, Bigard MA, Verwaerd JC: Treatment of gastric ulcer with lansoprazole or ranitidine. A multicentre clinical trial. Aliment Pharmacol Ther 1994, 8: 119-122

17. Classen M, Dammann HG, Domschke W, Huttemann W, Londong W, Rehner M, Simon B, Witzel L, Berger J: Omeprazole heals duodenal, but not gastric ulcers more rapidly than ranitidine. Results of two German multicentre trials. Hepatogastroenterology 1 985, 32:243-245

18. Cooperative Study Group: Double blind comparative study of omeprazole and ranitidine in patients with duodenal or gastric ulcer. Gut 1990, 31:653-656

19. Italian Cooperative Group on Omeprazole: Omeprazole 20 mg and ranitidine $150 \mathrm{mg}$ bid in the treatment of benign gastric ulcer. Hepatogastroenterology |99|, 38:400-403

20. Walan A, Bader JP, Classen M, Lamers CB, Piper DW, Rutgersson K, Eriksson S: Effect of omeprazole and ranitidine on ulcer healing and relapse rates in patients with benign gastric ulcer. $N$ Engl J Med 1989, 320:69-75

21. Choi KW, Sun HS, Yoon CM, Park KN, Muri YI, Chang R, Lee SI Chung JM, Yang US, Wong EC: A double blind, randomized, parallel group study of omeprazole and ranitidine in Korean patients with gastric ulcer. J Gastroenterol Hepatol I 994, 9: I I 8-I 23

22. Bader JP, Delchier JC: Clinical efficacy of pantoprazole compared with ranitidine. Aliment Pharmacol Ther I994, 8(suppl I):4752

23. Hotz J, Plein K, Schonekas H, Rose K: Pantoprazole is superior to ranitidine in the treatment of acute gastric ulcer. Scand ] Gastroenterol 1995, 30: III- II 5

24. Florent C, Audigier JC, Boyer J: Efficacy and safety of lansoprazole in the treatment of gastric ulcer: a multicentre study. Eur I Gastroenterol Hepatol 1994, 6: I I35- II 39

25. Witzel L, Gutz H, Huttemann W, Schepp W: Pantoprazole versus omeprazole in the treatment of acute gastric ulcers. Aliment Pharmacol Ther 1995, 9(1):19-24

26. Dekkers CP, Beker JA, Thjodleifsson B, Gabryelkewicz A, Bell NE, Humphries T]: Comparison of rabeprazole $\mathbf{2 0} \mathbf{~ m g}$ versus omeprazole $20 \mathrm{mg}$ in the treatment of active gastric ulcer- a European multicentre study. The European Rabeprazole Study Group. Aliment Pharmacol Ther 1998, I 2:789-795

27. Humphries TJ, Cloud ML, Enas N, Bassion S, McNamara M: Rabeprazole (E38 I 0), LY307640 achieves high rates of healing in active gastric ulcer. Gastroenterology | 996, I I 0(suppl): | 38

28. Di Mario F, Battaglia G, Leandro G, Grasso G, Vianello F, Vigneri S: Short-term treatment of gastric ulcer. A Meta-analytical evaluation of blind trials. Dig Dis Sci 1996, 4 I: I I08-I I3 I

29. Caro J, Salas M, Ward A: Healing and relapse rates of new proton-pump inhibitors versus omeprazole, ranitidine and placebo in gastroesophageal reflux disease. Evidence from randomized clinical trials. Clin Ther 200I, 23:998-1017

30. Poynard T, Lemaire M, Agostini H: Meta-analysis of randomized clinical trials comparing lansoprazole with ranitidine or famotidine in the treatment of acute duodenal ulcer. Eur / Gastroenterol Hepatol 1995, 7:661-665

31. Ulvertaft CN: Comments on the incidence and natural history of gastric and duodenal ulcer. Postgrad Med J 1968, 44:597-602

32. Kirk RM: Are gastric and duodenal ulcers separate diseases or do they form a continuum? Dig Dis Sci 198I, 26:149-154

33. Howden $\mathrm{CW}$, Hunt $\mathrm{RH}$ : The relationship between suppression of acidity and gastric ulcer healing rates. Aliment Pharmacol Ther 1990, 4:25-33

\section{Pre-publication history}

The pre-publication history for this paper can be accessed here:

http://www.biomedcentral.com/1471-230X/2/17/prepub 